\title{
Diagnostic value of spinal ultrasound compared to MRI for diagnosis of spinal anomalies in pediatrics
}

\author{
Nermeen A. Tawfik', Ahmed Tohamy Ahmed ${ }^{1 *}$, Tarek E. El-Shafei ${ }^{2}$ and Mohamed R. Habba ${ }^{1}$
}

\begin{abstract}
Background: Spinal dysraphism (SD) is a spectrum of congenital disorders. MRI is the gold standard technique for diagnosis of SD. Spinal ultrasonography (USG) can be used as a screening tool for SD in infants. The purpose of our study is to assess the diagnostic value of spinal USG in the diagnosis of spinal dysraphism in pediatrics compared to MRI as a gold standard technique. Our prospective, cross-sectional study involved 45 infants and children with suspected spinal dysraphism. All patients were subjected to supervision of their medical history, full neurological examination, spinal ultrasonography and anatomical spine assessment by conventional MRI examination including sagittal and axial T1W \& T2W, sagittal \& coronal STIR imaging. Comparison of spinal USG with MRI findings was done.

Results: There is excellent overall agreement between MRI and ultrasound diagnosis in the evaluation of spinal cord morphology and bony elements in patients aged $\leq 2$ years old ( $k=0.96$ and 0.98 ) respectively, and fair overall agreement between MRI and ultrasound diagnosis $(k=0.58)$ in patients aged $>2$ years old. The accuracy of spinal USG in diagnosis of spinal dysraphism in patients aged $\leq 2$ years old was as the following: specificity (94.5-100\%), sensitivity (84.3100\%), PPV (86.7-100\%) and NPV (85.7-100\%), as compared to MRI.

Conclusion: Spinal ultrasound can be used as a first-line screening investigation for SD; patients with USG abnormalities proceed to MRI. Spinal ultrasound is of no worthy value after the age of bone ossification, and MRI is the best modality of diagnosis in older pediatrics.
\end{abstract}

Keywords: Magnetic resonance imaging, Spinal ultrasonography, Spinal dysraphism

\section{Background}

Spinal dysraphism includes a spectrum of congenital disorders and it is caused by imperfect fusion of midline bony, mesenchymal and neural structures due to incomplete closure of the neural tube in early embryoneogenesis [1]. Spinal dysraphism is divided into two broad groups: spina bifida aperta (posterior protrusion of neural tissue through a bony vertebral defect with exposure of neural tissue, not covered by skin); and spina bifida occulta with and without a skin-covered back mass [2].

It is the most common congenital central nervous system (CNS) abnormality with myelomeningoceles

\footnotetext{
* Correspondence: Tohame_g@yahoo.com

'Department of Diagnostic Radiology, Faculty of Medicine, Suez Canal

University, Ismailia, Egypt

Full list of author information is available at the end of the article
}

occurring in up to 2 per 1000 live births, although recently, the incidence has been decreased by maternal dietary folate supplementation prior to and during pregnancy $[3,4]$.

Spinal magnetic resonance imaging (MRI) has been called the gold standard of screening for occult spinal dysraphism [5, 6], but it is time-consuming, costly and invasive which requires sedation or general anesthesia in infants. It is highly dependent on factors affecting resolution such as patient motion, physiological motion from cerebrospinal fluid (CSF) pulsation and vascular flow [7-9].

Spinal ultrasound can be used in the diagnosis of occult and non-occult spinal dysraphism, assessment of spinal cord tumors, vascular malformations and in birthrelated trauma cases [10]. Presence of cutaneous or subcutaneous anomaly of the lower back or an imperforate 
anus requiring a search for occult tethered spinal cord [11].

So the purpose of this study is to assess the diagnostic value of spinal ultrasound as a primary modality for diagnosis of spinal dysraphism in pediatrics compared to MRI as a gold standard tool.

\section{Methods}

This is a comparative cross-sectional, prospective singlecenter study approved by the local institutional ethics committee; written informed consent was obtained from parents of patients.

\section{Study population}

Our study consisted of a series of 45 infants and children with clinically suspected spinal cord anomalies and presented by skin-covered masses and midline cutaneous malformations of the back over a period of 2 years from October 2017 to September 2019.

Inclusion criteria involved the following: infants and children of any age clinically suspected to have spinal dysraphism or tethered cord having either (midline or paramedian back masses or dimples, midline skin discoloration, skin tags, hair tufts, hemangiomas of the back). Exclusion criteria involved (a) newborns with clinically suspected birth-related spinal cord injury, (b) absolute contraindications to MR imaging and (c) parents refusing to contribute in the study.

All patients were subjected to revision of their medical history, full neurological examination, spinal ultrasonography scan and anatomical spine assessment by conventional MRI examination including (sagittal and axial T1W \& T2W, sagittal \& coronal STIR imaging). Comparison of spinal ultrasonography (USG) with MRI findings as was performed.

\section{History and neurological examination}

Assessment of the following was done: (a) clinical history of skin-covered masses and midline cutaneous malformations of the back, (b) history of any neurological manifestations (urinary incontinence) or associated congenital anomalies.

\section{Spinal ultrasonography scan}

Spinal ultrasonography was done for all participants in the study by using two machines; (a) PHILIPS HD 11 $\mathrm{XE}$ using the high frequency array (L12-3), (b) SEIMENS ACUSON X300 using the high frequency linear probe(VF 10-5).

\section{Spinal ultrasonography technique protocol}

Patient was laying prone with head slightly higher than the feet to better fill the lower CSF space. A rolled towel was placed under the patient's abdomen to slightly widen the posterior inter-spinous spaces.

Routinely, sagittal and axial scans of the spinal cord were obtained using high-frequency ultrasound. Examination was done to assess (1) the spinal cord from the cranio-cervical junction to the conus medullaris, filum terminal and cauda equina; (2) bony vertebrae and its spinous process, whether there is a defect or no; and (3) any masses and whether (solid, cystic or heterogeneous).

\section{Magnetic resonance imaging}

All patients underwent lumbar MRI by using 1.5 Tesla MR scanner (Philips Medical Systems, Achieva). $5 \mathrm{CH}$ Spine Coil or $15 \mathrm{CH}$ Spine Coil was used.

\section{Patient's preparation}

Preparation included that patients not eat or drink $4 \mathrm{~h}$ prior to examination due to required sedation. Any metallic objects were removed. The patient lied in supine position. Sedation was required in 20 children aged $<2$ years old by using chloral hydrate.

\section{MRI protocol and technique}

Sagittal, fast spin-echo T1- and T2-W sequences (3$\mathrm{mm}$-thick slices) were done for the whole spine. Sagittal T1WIs were obtained with $\mathrm{TR}=600 \mathrm{~ms}$ and $\mathrm{TE}=30$ ms. Axial and sagittal T2WI were obtained with TR = $3000 \mathrm{~ms}, \mathrm{TE}=120 \mathrm{~ms}$. Images were obtained with an interslice gap of $5.2 \mathrm{~mm}$, slice thickness of $4 \mathrm{~mm}$ and a matrix size of $512 \times 512$.

Axial T1-W and T2-W images are acquired through any abnormality. Children with scoliosis and/or suspected spinal dysraphism routinely have axial T1-W images through the conus and filum terminale that may not be visible on sagittal imaging. Sagittal and coronal STIR (short tau inversion recovery) sequences with $\mathrm{TR}=3000 \mathrm{~ms}$ and $\mathrm{TE}=40 \mathrm{~ms}$ was done for all patients to detect if lipomas of filum terminale.

Unlike most adult spine imaging protocols, groups of axial images through disc levels are not applied because degenerative disc disease is rare.

\section{Spinal ultrasonography and MRI image analysis}

MRI findings were interpreted by two specialtycertified radiologists who were blinded with ultrasound findings.

Spinal cord morphology

- Presence of two hemicords

- Level of cord termination (tethered cord or not; low conus medullaris considered below L2).

- Expansion of central spinal canal

- Displacement of the cord (dorsal/ventral) 
- Conus medullaris thickness (normal thickness up to $4 \mathrm{~mm}$ )

- Filum terminale thickness (any fibrous or lipomatous ending; thickened filum terminale $>2$ $\mathrm{mm})$

- Cauda equina and nerve roots

- The surrounding subarachnoid space (if masses or expansion)

The associated pathology

- Back swelling (there is a neural element, fat or CSF?; neural placode, if present; is in flush with skin or not)

- Skin dimple (connected to cord or not)

- Sacral sinus (connected to cord or not)

Bony element pathology

- Presence of defective spinous process or not (spina bifida occulta)

- Vertebral morphology (ex. hemivertebrae or segmented vertebra)

- Sacral agenesis

\section{Statistical analysis}

Statistical analysis and tests were specified according to the variable type. A commercially available IBM Statistical Package for Social Sciences software (SPSS; 21st edition, IBM, USA) was used.

Results of the spinal USG were compared with those of the MRI, and the predictive values of spinal USG were calculated by obtaining positive predictive values (PPV), negative predictive values (NPV), sensitivity, specificity and total accuracy of the spinal USG.

Continuous data were expressed as mean \pm standard deviation and categorical data as percentage. Chisquared test was used to compare between the qualitative data expressed as number and percentage. Agreement between the spinal USG diagnosis and MRI diagnosis was determined using the kappa statistic (As a rule of thumb, $\kappa=1$ indicates perfect agreement, $0.8-<$ 1 is excellent agreement, $0.6-<0.8$ is good agreement, $0.4-<0.6$ is fair agreement, $>0-<0.4$ is poor agreement, and $\kappa=0$ is agreement by chance alone). Also, the inter-observer reliability and agreement of detected MRI findings was determined by using Kappa test.

\section{Results}

Demographic distribution of study population

Fourty five patients were subjected to our study with age range of 2 months - 12 years and a mean age of $15.6 \pm 13$ months. The studied patients were subdivided into two groups, either $>2$ years old or $\leq 2$ years old.
The patient group of $\leq 2$ years old involved 30 patients, while the patient group of $>2$ years old involved 15 patients. Study population represented 26 females (57.8\%) and 19 males $(42.2 \%)$.

\section{Distribution of study population according to clinical presentation, associated anomalies and spinal segments involved}

As represented in Table 1, variable clinical presentations were observed, and some cases shared more than one presentation.

The associated anomalies among our study population involved hydrocephalus, paraplegia with patulous anus, congenital scoliosis, renal anomalies, and lower limb anomalies. The most common associated anomaly was hydrocephalus (27\%). Urinary incontinence was found in 31 patients $(68 \%)$. Neurological abnormalities was found in 38 patients (84.5\%). Eleven cases had Chiari syndrome (24\%).

Lumbosacral spine was the most common region involved in 32 patients (71.1\%; Figs. 1, 2, 3 and 4). The dorsolumbar region was involved in 8 patients (17.8\%) and the sacrococcygeal region in 5 patients (11.1\%).

\section{Detailed distribution of study population according to different types of spinal dysraphism}

Open spinal dysraphism was found in 27 patients (60\%). Closed SD was found in 14 patients (31.1\%). Four cases shared both closed and open SD (8.9\%; Tables 2 and 3).

Detailed agreement between USG and MRI according to different types of spinal dysraphism was mentioned and declared in Table 4.

Detailed agreement between ultrasonography and MRI findings in terms of spinal cord morphology and bony element in patients aged $\leq \mathbf{2}$ years old

Our study correlated spinal USG with MRI findings to detect the level of agreement as regards spinal cord morphology in patients aged $\leq 2$ years old. We found higher levels of correlation in the detection of spinal

Table 1 Distribution of study population in terms of clinical presentation

\begin{tabular}{lll}
\hline Clinical presentation & No. & Frequency (\%) \\
\hline Cystic back swelling & 37 & $82.2 \%$ \\
Motor abnormalities & 9 & $20.2 \%$ \\
Skin dimple & 8 & $17.8 \%$ \\
Congenital scoliosis & 5 & $11.1 \%$ \\
Lower limb anomalies & 5 & $11.1 \%$ \\
\hline
\end{tabular}




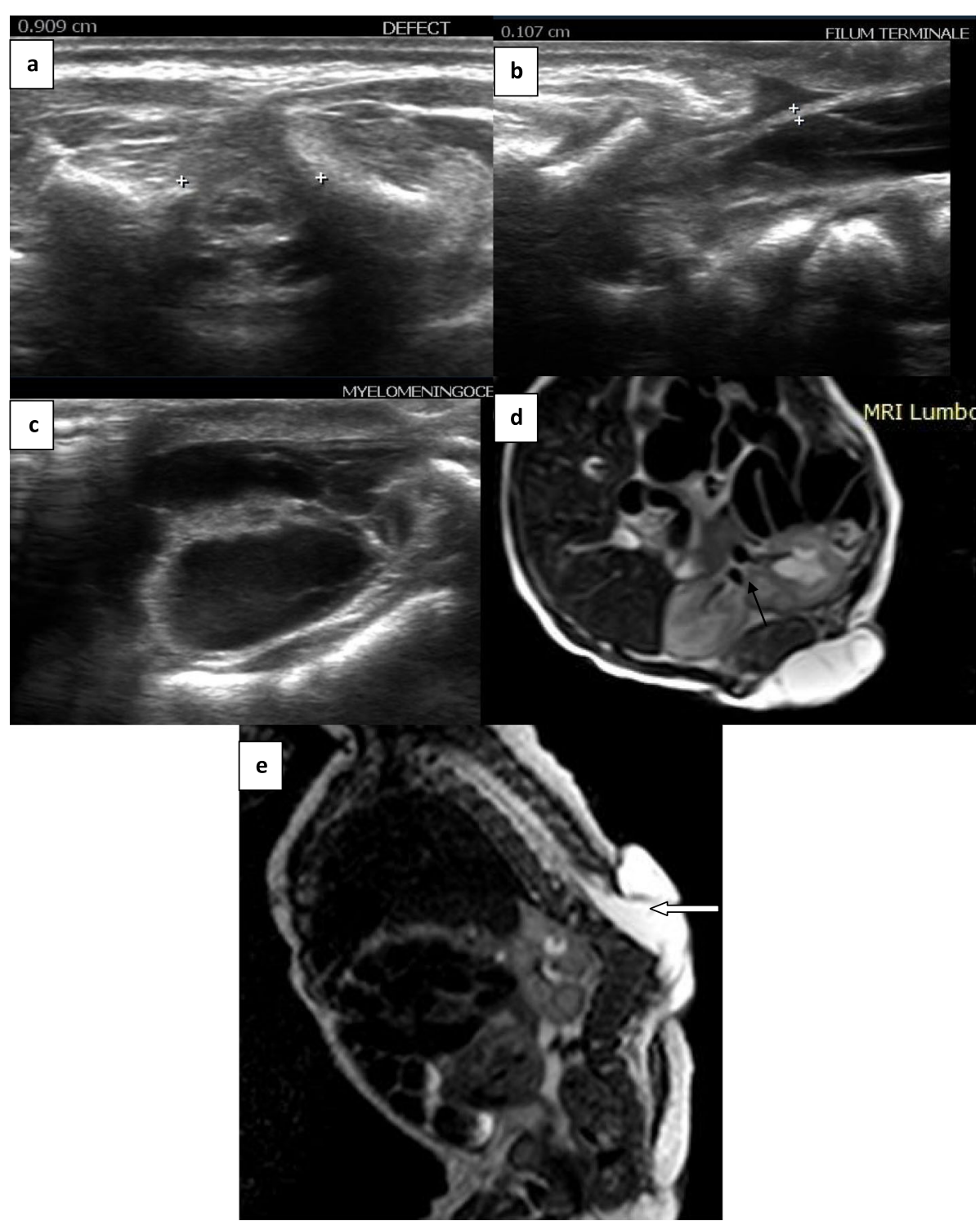

Fig. 1 Six-day-old female neonate presented with lumbar swelling and hydrocephalus, paraplegic with patulous anus, horse shoe kidney and vertebral anomalies. a Transverse USG showed defective spinous process with neural element passing through the defect and neural placode is not in flush with the skin. $\mathbf{b}$ Longitudinal USG showed filum terminale passing through the spinal defect. $\mathbf{c}$ Longitudinal USG showed cystic lesion showing CSF and nerve roots within (myelomeningocele). d Axial T2W MRI showed associated renal anomaly (horse shoe kidney, black arrow). e Sagittal T2W MRI showed defective L1 spinous process with all downward posterior components and myelomeningocele passing through the defect (white arrow). Final diagnosis is Myelomeningocele with associated vertebral anomalies (segmental spinal dysgenesis), agreement frequency between ultrasound and MRI findings = 94\% (segmental spinal dysgenesis was missed by ultrasound)

cord displacement, detection of two hemicords and detection of central spinal canal dilatation (100\%).

For evaluation of spinal cord morphology in patients less than 2 years old, there was excellent overall agreement between MRI diagnosis and ultrasound diagnosis $(\kappa=0.96)$ and $p$ value $<0.001$ (Table 5).

Regarding detection of bony element involvement in patients less than 2 years old, there was excellent overall agreement between MRI and ultrasound diagnosis $(\kappa=$ 0.98, Table 6).

The chi-square test revealed that the agreement between MRI and ultrasound diagnosis as regards spinal cord morphology diagnosis was seen in $88 \%(n=26)$ of patients and partial agreement was seen in $12 \%(n=4)$ of patients. Agreement between MRI and ultrasound diagnosis as regards detection of bony element 


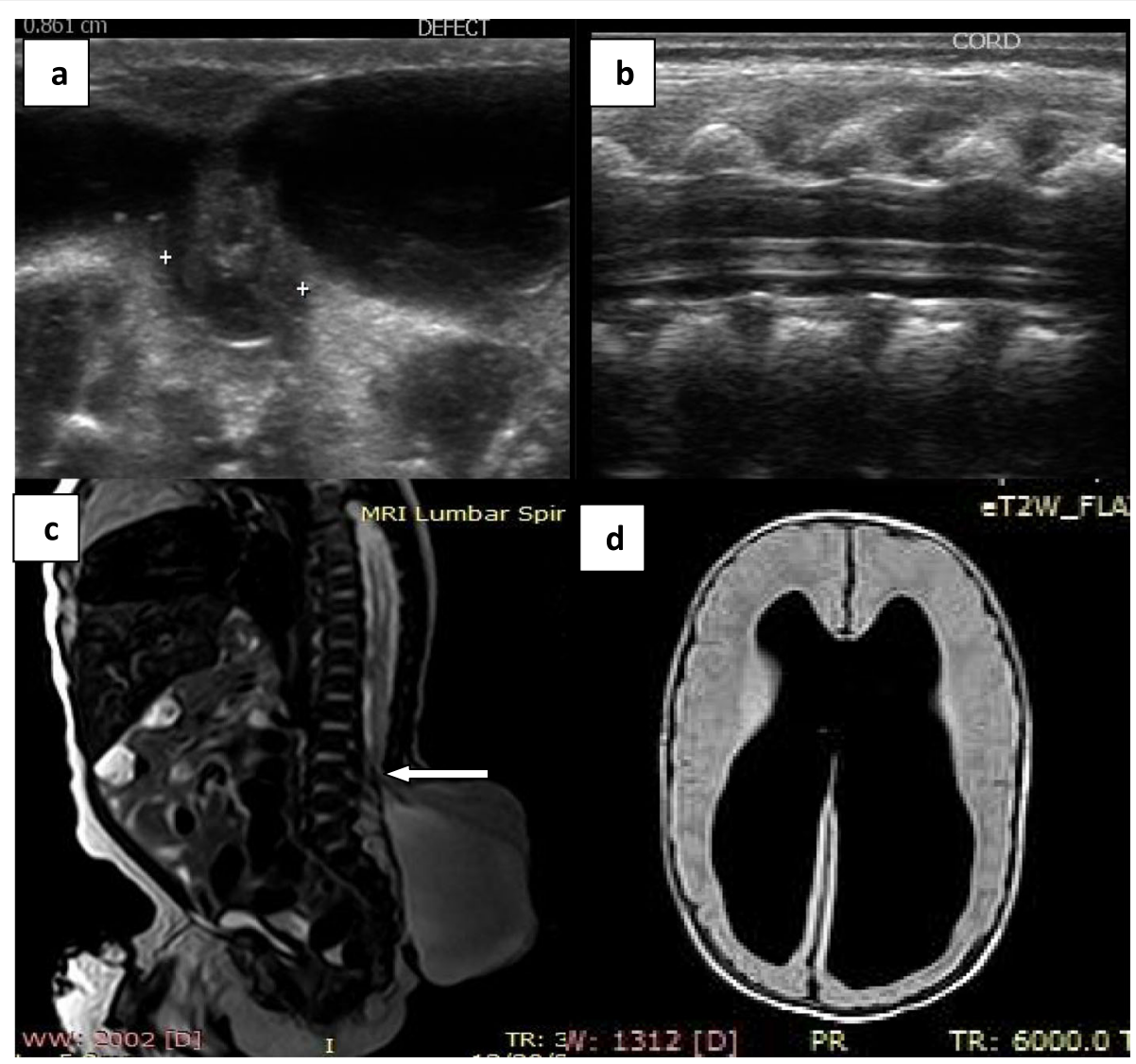

Fig. 2 Thirty-five-day-old infant presented with a large lumbar cystic swelling and paraplegia. a Transverse USG showed defective spinous process with CSF and nerve roots passing through it. b Longitudinal USG showed dilatation of central spinal canal with fluid (hydromyelia). c Sagittal STIR MRI showed defective spinous processes (white arrow), large lumbar swelling with CSF and nerve roots (myelomeningocele), and high signal fluid intensity noted within the spinal cord in keeping with syringohydromyelia (arrow). d Axial FLAIR MRI of brain showed hydrocephalus (Chiari II). Final diagnosis is Arnold-Chiari II Syndrome (myelomeningocele with syringohydromyelia and hydrocephalus), agreement frequency between ultrasound and MRI findings $=100 \%$

involvement was seen in $94 \%(n=28)$ of patients and partial agreement was seen in $6 \%(n=2)$.

Detailed agreement level between ultrasonography and MRI findings in terms of spinal cord morphology and bony element in patients of $>2$ years old

It was found that there is the same agreement level in all items of comparison either in spinal morphology or bony elements $(\approx 33.3 \%)$.

In terms of detection of spinal morphology and bony element involvement in patients of $>2$ years old, there was fair overall agreement between MRI diagnosis and ultrasound diagnosis $(\kappa=0.58)$. Agreement between MRI diagnosis and ultrasound diagnosis was seen in $33.3 \%(n=5)$ of patients and no agreement was seen in $66.7 \%(n=10)$.
Accuracy of ultrasonography and MRI findings in terms of spinal cord morphology and bony element in patients with spinal dysraphism

It was found that the accuracy of spinal ultrasound in the diagnosis of spinal dysraphism in patients aged $\leq 2$ years old are as the following: specificity levels ranging from $94.5-100 \%$, sensitivity ranging from $81.8-100 \%$, positive predictive value ranging from $84.3-100 \%$ and negative predictive value ranging from $86.7-100 \%$, as compared to MRI.

The accuracy of spinal ultrasound in diagnosis of spinal dysraphism in comparison with MRI in patients (aged > 2 years old) was as the following; spinal USG displayed specificity of $100 \%$ and sensitivity of $33.3 \%$, positive predictive value of $66.7 \%$, and negative predictive value of $49 \%$, as compared to MRI. 


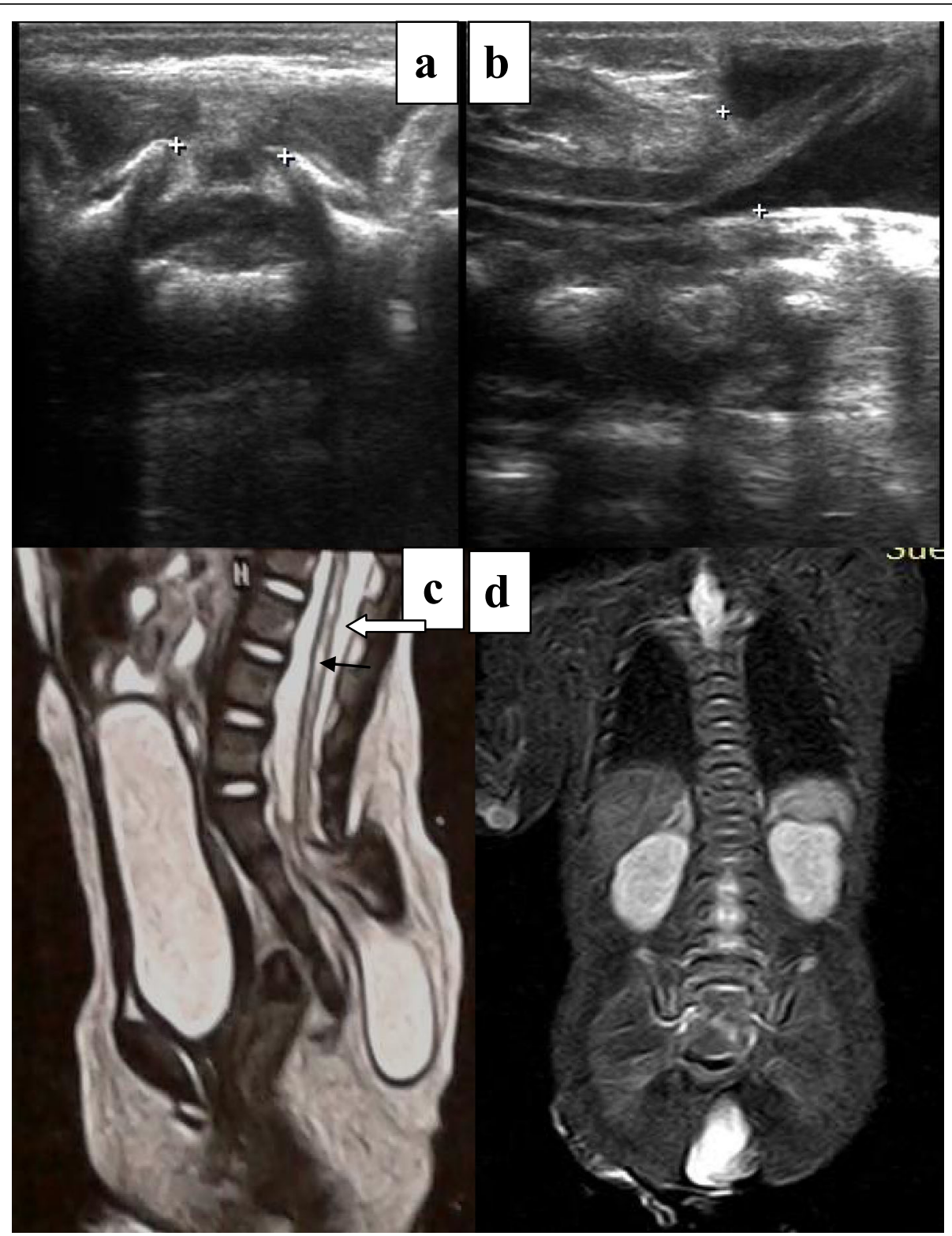

Fig. 3 One-year-old female infant presented with back swelling. a Transverse USG showed defective spinous process at L5 level. b Longitudinal USG showed dilated central spinal canal (hydromyelia), cystic dilatation at its end, and dilated surrounding subarachnoid space (associated meningeocele). c Sagittal T2WI showed hydromyelia (black arrow), cystic dilatation of central spinal canal (white arrow), tethered cord and noted neurogenic bladder. $\mathbf{d}$ Coronal T2WI showed cystic lesion (Myelcystocele). Final diagnosis is terminal myelocystocele. Partial agreement between USG and MRI, conus medullaris and filum terminal were not assessed properly by USG; agreement frequency $=88 \%$

There was excellent complete overall agreement and reliability between the two reviewers in the interpretation of MRI data $(\kappa=1)$. Both reviewers were blinded to USG data.

\section{Discussion}

Spinal ultrasound is becoming remarkably accepted as a first-line screening imaging modality used in neonates suspected of spinal dysraphism [12]. Motion artifacts, which can considerably reduce the quality of MRI in young children, play a minor role during the real-time ultrasound. The diagnostic value of spinal ultrasonography is nearly similar to MRI for diagnosis of main spinal anomalies in infants $[13,14]$.

According to the demographic profile; the age of our study group ranged from 2 months to 12 years and a 


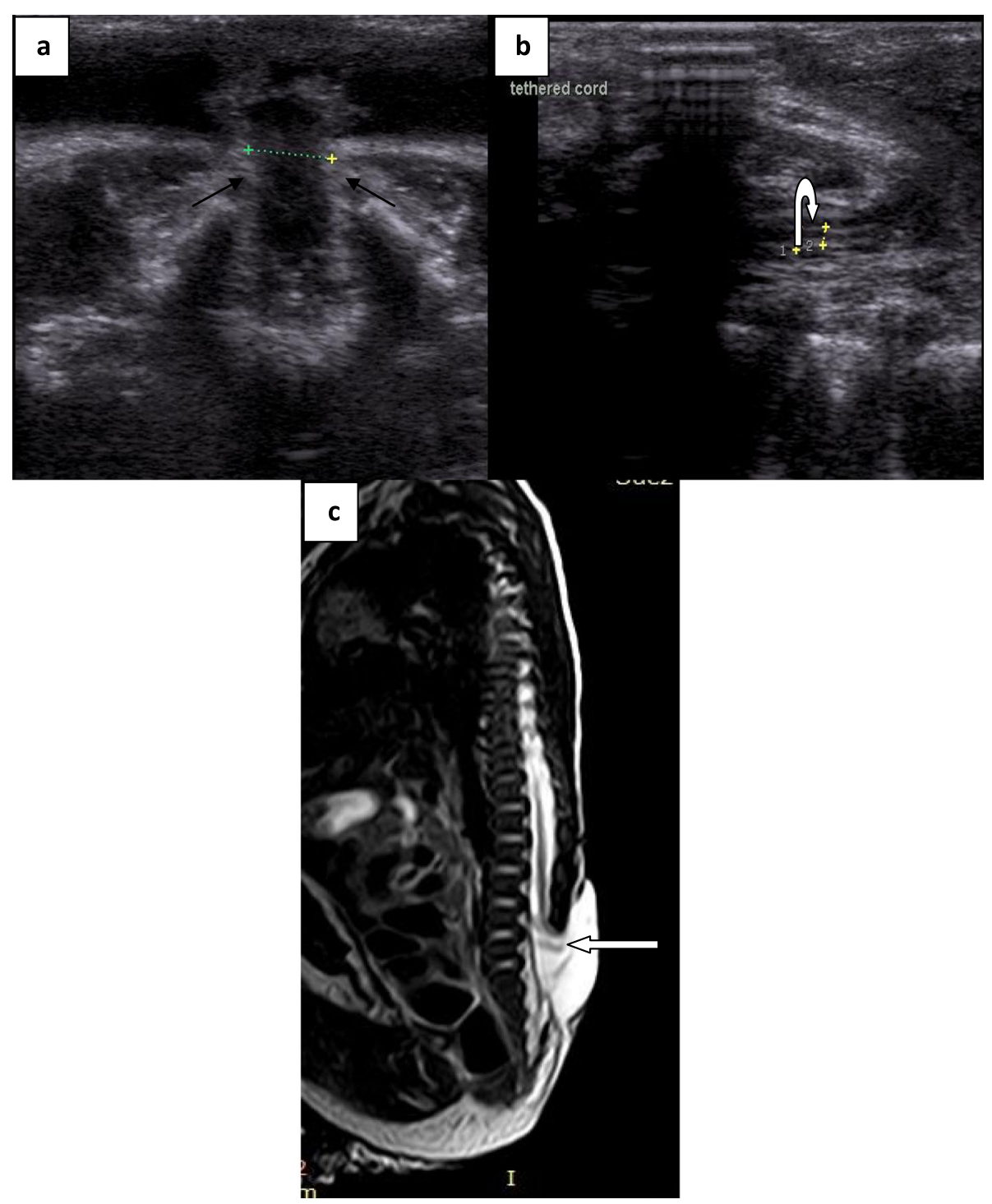

Fig. 4 A one-day-old male neonate presented with cystic back swelling, paraplegia and patulous anus. a Transverse 2D ultrasound scans demonstrated spinous process bony defect of L5 level with CSF and nerve roots passes through out (black arrows). b Longitudinal 2D ultrasound scan demonstrated tethered cord (curved arrow). c Sagittal T2W1 showed tethered cord with lumbar myelomeningocele (neural placode is not in flush with the skin, white arrow). Final diagnosis is myelomeningocele, agreement frequency between ultrasound and MRI findings $=100 \%$

mean age of $15.6 \pm 13$ months. The patient group of $\leq 2$ years old involved 30 patients, while the patient group of $>2$ years old involved 15 patients. Study population represented 26 females (57.8\%) and 19 males (42.2\%).

In other study by Kumari et al. which examined 66 patients (age ranged from 17 days to 13 years). Most of the children were $\leq 2$ years old. Fourty $(66.6 \%)$ patients were females and $26(33.3 \%)$ were males. They found that swelling in the back was also the commonest clinical feature $(77.2 \%)$ [15].

Mehta et al. studied 50 patients and found that the most common anomalies were type II Arnold-Chiari malformation with lumbar meningomyelocele (34\%), spina bifida occulta (22\%), and diastmatomyelia (18\%) [16].

In another study by Dhingani et al., where age group of the studied patients ranged from 2 days to 16 years. $84.21 \%$ patients were $<10$ years old, and the neonatal period was the most common presenting age group accounting for $39.47 \%$ of total cases. The most common clinical finding at presentation was also midline back swelling (60.53\%); however, the next common finding was urinary incontinence (47.37\%), followed by skin dimple in back (28.95\%), fecal 
Table 2 Detailed distribution of study population in terms of different types of spinal dysraphism

\begin{tabular}{lll}
\hline Spinal dysraphism type & No. & Frequency \\
\hline Opened spinal dysraphism & 27 & $60 \%$ \\
- Myeolomeningocele & 19 & $42.2 \%$ \\
- Myelocele & 8 & $17.8 \%$ \\
Closed spinal dysraphism & 14 & $31.1 \%$ \\
- Distomatomyelia with segmental spinal dysgenesis & 4 & $9 \%$ \\
- Dermal sinus & 2 & $4.5 \%$ \\
- Lipomyelomeningocele with associated dermal sinus & 2 & $4.5 \%$ \\
- Caudal regression syndrome & 2 & $4.5 \%$ \\
- Myelocystocele & 1 & $2.3 \%$ \\
- Tethered cord & 3 & $6.3 \%$ \\
Open + closed spinal dysraphism & 4 & $8.9 \%$ \\
-Myelomeningocele with caudal regression & 2 & $4.45 \%$ \\
-Myelomeningocele with segmental spinal dysgenesis & 2 & $4.45 \%$ \\
\hline
\end{tabular}

incontinence (21.05\%), hair tuft (3.33\%), and dermal sinus $(3.33 \%)$ [17].

In our study, lumbosacral spine was the most common region involved in 32 patients (71.1\%).

We shared comparable results with Dhingani et al. who found that the lumbosacral spine was the most commonly involved spinal segment found in 52.63\% of patients, followed by sacrococcygeal region (34.21\%) [17].

Our study results as regards spinal ultrasound are comparable with study by Dhingani et al. which showed that the most common anomaly was tethered cord seen in $23(79.31 \%)$ patients, syrinx (62.06\%), MMC (48.27\%), and lipomyelomeningeocele (27.58\%) [17]. And another study by Taahira Nishtar et al., which revealed that 2 of the studied 53 patients (4\%) has diastematomyelia [18].

Table 3 Distribution of study population in terms of type of spinal dysraphism

\begin{tabular}{lll}
\hline Spinal dysraphism type & No. & Frequency (\%) \\
\hline Myelomeningocele & 23 & $51.2 \%$ \\
Segmental spinal dysgenesis & 6 & $13.3 \%$ \\
Diastomatomyelia & 4 & $9 \%$ \\
Caudal regression syndrome & 4 & $9 \%$ \\
Dermal sinus & 4 & $9 \%$ \\
Myelocystocele & 1 & $2.2 \%$ \\
Tethered cord & 3 & $6.6 \%$ \\
Myelocele & 8 & $17.8 \%$ \\
Lipomyelomeningocele & 2 & $4.4 \%$ \\
\hline
\end{tabular}

Dhingani et al. displayed that open SD was found in $14(36.84 \%)$ patients and closed SD was seen in $24(63.16 \%)$ patients. It was found that $26.32 \%$ of patients with closed SD had subcutaneous mass, and 14 patients $(36.84 \%)$ were not having subcutaneous mass. In open SD, myelomeningocele was the most common anomaly accounting for 14 (36.84\%) cases [17].

Both spinal USG and MRI were performed in whole 45 cases. Agreement between findings of these two modalities was studied. There were 10 cases aged $>2$ years revealed no agreement between MRI and USG findings that there was acoustic shadowing from posterior spinal elements ossification, so ultrasound was unreliable and we could not reach the primary diagnosis by this modality (Fig. 5). Thus, statistics was divided to age groups $\leq 2$ years old (before complete ossification of spinal elements) and > 2 years old (after ossification of spinal elements) in order to reach significant results.

We agreed with Dhingani et al.'s study which showed that 23 out of 29 patients (79.31\%) showed full agreement between spinal USG and MRI examinations, and 6 out of 29 patients (20.69\%) showed partial agreement. In these six cases with partial agreement; spinal USG missed tethered cord and syrinx in three cases, small lipomatous component in one case of lipomyelomeningeocele, one case of intradural lipoma, and one case of split cord associated with myelomeningocele [17].

In another study by Hughes et al., ultrasound showed full agreement with MRI in 6 of 15 patients (40\%), partial agreement in 7 of 15 patients (47\%) and no agreement in 2 of 15 patients. Ultrasound missed some 
Table 4 Detailed agreement between ultrasound and MRI of different types of spinal dysraphism

\begin{tabular}{llll}
\hline Spinal dysraphism & No. & Total agreement & Partial agreement \\
\hline Myelomeningocele & $23(51.2 \%)$ & $19(42.2 \%)$ & $4(9 \%)$ \\
Segmental spinal dysgenesis & $6(13.3 \%)$ & & \\
Dermal sinus & $4(9 \%)$ & $4(9 \%)$ & \\
Diastomatomyelia & $4(9 \%)$ & $2(4.4 \%)$ & $2(4.4 \%)$ \\
Caudal regression syndrome & $4(9 \%)$ & & $2(4.4 \%)$ \\
Lipomyelomeningocele & $2(4.4 \%)$ & & $1(2.2 \%)$ \\
Myelocystocele & $1(2.2 \%)$ & $2(4.4 \%)$ & $1(2.2 \%)$ \\
Tethered cord & $3(6.6 \%)$ & $8(17.8 \%)$ & \\
Myelocele & $8(17.8 \%)$ & &
\end{tabular}

findings in some cases as dorsal dermal sinuses, fatty filums, terminal lipoma, partial sacral agenesis, hydromyelia and low-lying cords. However, overall, in 12 of 13 (92\%) cases with abnormal MRI, ultrasound identified at least one of the concurrent abnormalities. No agreement was found between ultrasound and MRI in two cases, one being false-positive and the other false-negative. This resulted in an overall false-negative diagnosis in one of 12 patients (8\%) with abnormal MRI, and an overall false-positive diagnosis in one of 3 patients with a normal MRI [19].

Dhingani et al., showed that the primary anomaly was identified and diagnosed on USG in 23 of 25 (92\%) cases, while the primary anomaly was diagnosed in 25 cases by MRI (4 cases were having isolated vertebral anomalies or sacrococcygeal agenesis). USG is not an ideal modality for identifying other abnormalities associated with spinal dysraphism such as tethered cord, syrinx, and split cord, as compared to MRI [17].

Table 5 Agreement between USG and MRI findings in terms of spinal cord morphology in patients aged $\leq 2$ years old

\begin{tabular}{ll}
\hline Item of comparison & Frequency (\%) \\
\hline Detection of cord displacement & $100 \%$ \\
Detection of two hemicords displacement & $100 \%$ \\
Level of cord end (cord tethered or not) & $95.6 \%$ \\
Detection of central spinal canal expansion & $100 \%$ \\
Assessment of conus medullaris thickness & $89 \%$ \\
Assessment of filum terminal thickness (any fibrous & $89 \%$ \\
or lipomatous ending) & \\
Assessment of cauda equina and nerve roots & $89 \%$ \\
Evaluation of the surrounding subarachnoid space & $94.5 \%$ \\
\hline
\end{tabular}

Spinal USG has less sensitivity compared to MRI in detecting closed type of spinal anomalies or other findings associated with the primary anomaly, various vertebral anomalies and kyphoscoliotic deformity. MRI is also superior in identifying the exact extent of detected anomaly such as intraspinal extension of lipomatous tissue; the level, extent and type of split cord; extent of vertebral agenesis; and shape and level of conus termination in the case of caudal regression syndrome (CRS). Thus, MRI identifies all concurrent abnormalities, gives a complete diagnosis, and helps in planning better management.

This study had also some limitations: (1) Spinal ultrasonography is not beneficial after the age of 2 years; (2) most cases of closed spinal dysraphism are not complaining at all or presented to neurosurgery and neurology clinics when they are older either presented by congenital scoliosis or urinary incontinence (after the age of 5 years), so these cases are underdiagnosed by ultrasound, and MRI is the only best modality for their diagnosis. Studies with larger samples are needed to provide more realistic representative results than smaller ones to increase external validity.

\section{Conclusion}

Spinal ultrasound can be used as the first-line screening investigation for $\mathrm{SD}$, and those with detected USG abnormalities proceed to spinal MRI. Spinal

Table 6 Detailed agreement between USG and MRI findings regarding detection of bony element in patients $\leq 2$ years old

\begin{tabular}{ll}
\hline Bony element & Frequency (\%) \\
\hline Presence of defective spinous process & $100 \%$ \\
Vertebral morphology & $100 \%$ \\
Sacral agenesis & $96.7 \%$ \\
\hline
\end{tabular}




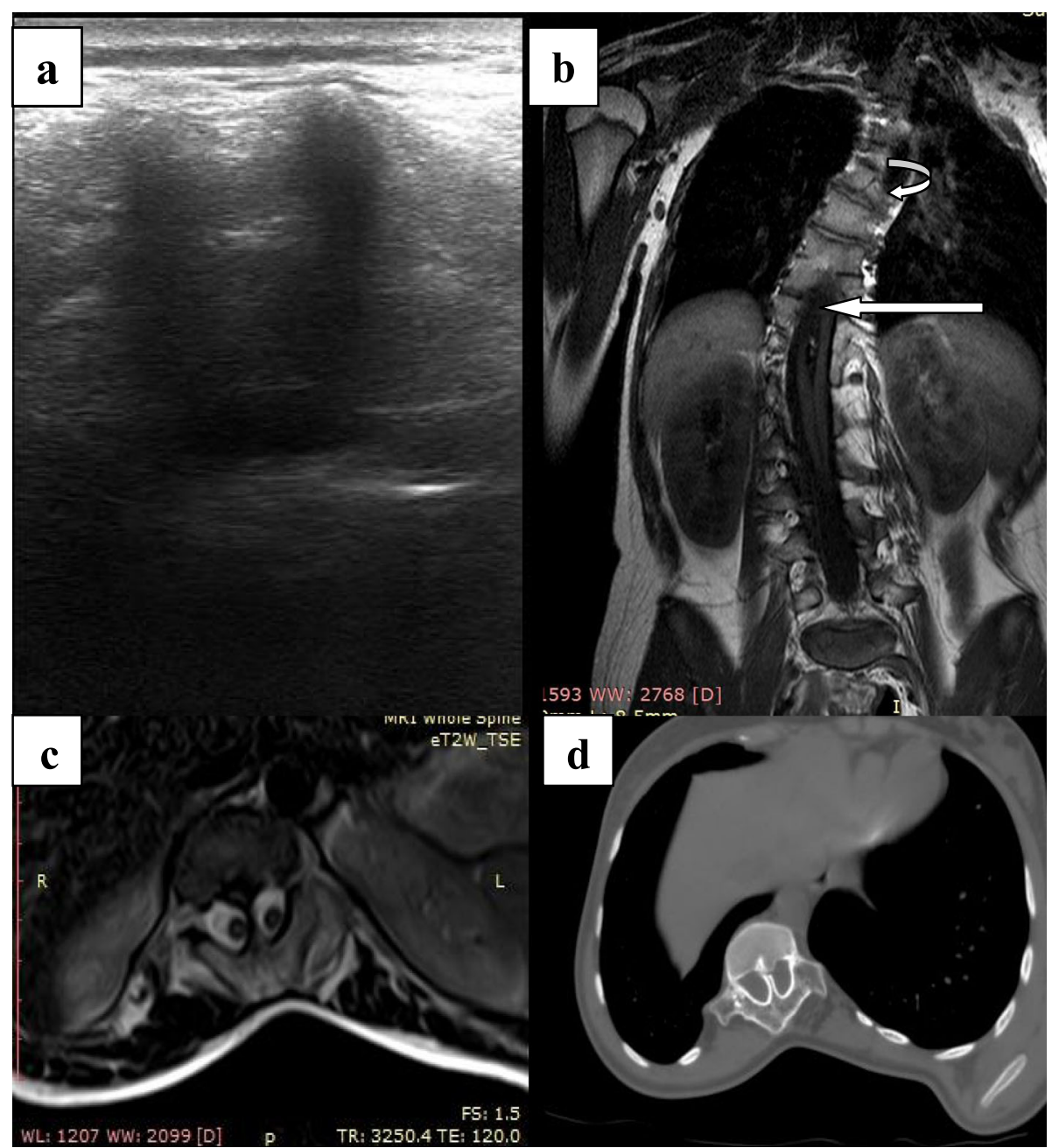

Fig. 5 Eight-year-old child presented with congenital scoliosis. a Ultrasound showed no apparent findings due to bone closure. b Coronal T1WI showed two cords with bony septum seperation at L1 level (white arrow), and abnormal vertebral morphology (hemivertebrae, curved arrow). c Axial T2WI showed two cords within one dural sac which are seperated by bony septum at L1 level (type I diastomatomyelia). d Complementary axial images of plain CT (done exceptionally) showed bony spur at L1 level. Final diagnosis is diastomatomyelia (type I). No agreement between USG and MRI findings.

ultrasound is an easy diagnostic modality; it is safe, non-invasive, inexpensive, does not require sedation and can be performed portably. Spinal ultrasound is of no worth value after the age of bone ossification, so MRI is the best imaging modality for diagnosis of $\mathrm{SD}$ in older pediatrics.

\section{Abbreviations}

CRS: Caudal regression syndrome; MMC: Myelomeningocele; SD: Spinal dysraphism; Spinal USG: Spinal ultrasonography

\section{Acknowledgements}

Not applicable

\section{Authors' contributions}

NA helped in preparation of study methodology, data collection and analysis of data. AT participated in formulation of the study, preparation of methodology, data collection, analysis and revision of collected data, and writing the paper. TE participated in revision of the study methodology and collected data. MR participated in revision of the study methodology and collected data. All authors have read and approved the manuscript.

\section{Funding}

The authors state that this work has not received any funding.

\section{Availability of data and materials}

The dataset used and/or analyzed during the current study are available from the corresponding author on reasonable request.

\section{Ethics approval and consent to participate}

This study was approved by the local institutional ethics committee (Committee of Scientific Research Ethics (CSRE), Suez Canal University, Egypt); written informed consent was obtained from all patients. The reference number is not applicable and/or not available.

\section{Consent for publication}

Consent for publication was obtained from the patients. 


\section{Competing interests}

The authors of this manuscript declare no relationships with any companies, whose products or services may be related to the subject matter of the article.

\section{Author details}

'Department of Diagnostic Radiology, Faculty of Medicine, Suez Canal University, Ismailia, Egypt. ${ }^{2}$ Department of NeuroSurgery, Faculty of Medicine, Suez Canal University, Ismailia, Egypt.

Received: 1 November 2019 Accepted: 5 January 2020

Published online: 17 January 2020

\section{References}

1. Micu R, Chicea AL, Bratu DG et al (2018) Ultrasound and magnetic resonance imaging in the prenatal diagnosis of open spina bifida. Med Ultrason 2;20(2):221-227

2. Kumar J, Afsal M, Garg A (2017) Imaging spectrum of spinal dysraphism on magnetic resonance: a pictorial review. World Journal of Radiology 9(4):178190

3. Verhey LH, Branson HM, Makhija M et al (2010) Magnetic resonance imaging features of the spinal cord in pediatric multiple sclerosis: a preliminary study. Neuroradiology 52(12):1153-1162

4. Ghi T., Dall'asta A., Pilu G., et al (2018) Neural tube defects. In : M. E. D'Alton, H. Feltovich, E. Gratacós et al., (Elsevier eds) Obstetric Imaging: Fetal Diagnosis and Care. (2 ${ }^{\text {nd }}$ Edition). Copel, Joshua A, pp 213-226.

5. O'Neill BR, Gallegos D, Herron A et al (2016) Use of magnetic resonance imaging to detect occult spinal dysraphism in infants. J Neurosurg Pediatr 19(2):217-226

6. Huisman T, Rossi A, Tortori-Donati P (2012) MR imaging of neonatal spinal dysraphia: What to consider? Magnetic Resonance Imaging Clinics of North America 20(1):45-61

7. Ravi N, Naveen KG, Nagaraj BR et al (2014) Role of MRI in the evaluation of spinal dysraphism. SSRG Int J Med Sci 2:31-44

8. Tehranzadeh J, Andrews C, Wong E (2000) Lumbar Spine Imaging Radiologic Clinics 38(6):1207-1253

9. Alamdaran SA, Mohammadpanah N, Zabihian S et al (2017) Diagnostic value of ultrasonography in spinal abnormalities among children with neurogenic bladder. Electronic Physician 9(6):4571-4576

10. Unsinn KM, Geley T, Freund MC et al (2000) USG of the spinal cord in newborns: spectrum of normal findings, variants, congenital anomalies, and acquired diseases. Radiographics 20(4):923-938

11. Tomà P (2005) Spine and spinal cord sonography. Pediatric Neuroradiology: Brain. Springer, Berlin Heidelberg, pp 1715-1723

12. Gunes O, Maud P, Donna S et al (2019) Ultrasound to evaluate neonatal spinal dysraphism: a first-line alternative to CT and MRI. J Neuroimaging. https://doi.org/10.1111/jon.12649

13. Upasani V, Ketwaroo PD, Estroff JA et al (2016) Prenatal diagnosis and assessment of congenital spinal anomalies: review for prenatal counseling. World Journal of Orthopedics 7(7):406-417

14. Mottet N, Saada J, Jani J et al (2016) Sonographic evaluation of fetal conus medullaris and filum terminale. Fetal Diagnosis and Therapy 40(3):224-230

15. Kumari MV, Chandra S, Aemjal R (2016) Role of MRI in evaluation of suspected spinal dysraphism. J Evolution Med Dental Sci 5(17):879-884

16. Mehta DV (2017) Magnetic resonance imaging in paediatric spinal dysraphism with comparative usefulness of various magnetic resonance sequences. J Clin Diagn Res 11(8):Tc17-Tc22

17. Dhingani $\mathrm{D}$, Boruah $\mathrm{D}$, Dutta $\mathrm{H}$ et al (2016) Ultrasonography and magnetic resonance imaging evaluation of pediatric spinal anomalies. Journal of Pediatric Neurosciences 11(3):206-212

18. Nishtar T, Elahi A, labaletal N (2011) To determine the frequency of accuracy of MRI in diagnosis of rare disorder of spinal dysraphism. J Med Sci 19(4): 195-199

19. Hughes JA, De Bruyn R, Patel K et al (2003) Evaluation of spinal ultrasound in spinal dysraphism. Clin Radiol 58(3):227-233

\section{Publisher's Note}

Springer Nature remains neutral with regard to jurisdictional claims in published maps and institutional affiliations.

\section{Submit your manuscript to a SpringerOpen ${ }^{\circ}$ journal and benefit from:}

- Convenient online submission

- Rigorous peer review

- Open access: articles freely available online

- High visibility within the field

- Retaining the copyright to your article

Submit your next manuscript at $\boldsymbol{\nabla}$ springeropen.com 